\title{
Por Llanos y Montañas: Creemos en la Historía: An Inquiry into the 1961 Cuban Literacy Campaign using Photographic Representation
}

\author{
Joanne C. Elvy \\ Algoma University
}

\begin{abstract}
In 1961, the Revolutionary government in Cuba initiated a literacy campaign that became the vehicle for social change in the country affirming the value of education, healthcare, citizenship, professional development and the concept of family and community. As an artful researcher noting the impact of this educational initiative many years later, my original intent was to simply incorporate photographs into the research as a kind of language, a felt knowledge. However, the photograph became a vital part of the methodological process as an important research tool, as would be the reader's interaction with the finished piece as it is presented (Cixous, Barthes, Jongeward, Robins, et al.). Together text and image present a multiplicity of readings in the deliberate disruption of linear flow that might be akin to a theatre piece. As a multitude of stories are presented in poetic form as part of a shared experience, this functions as an extended metaphor for the complexity of Cuba within a broader historical forum (Irwin-Zarecka, Steedman, Thelen, et al.).
\end{abstract}

How does one measure a "knowing" that does not fit within the prescribed format of collecting data? As an artful researcher I have documented the reflections of Cuban women who, as young teenagers in 1961, were volunteer "teachers" in the Cuban Literacy Campaign. Their decision to participate in this collective movement during the early years of their country's Revolution was in itself a pedagogical moment, for it introduced them to the possibility of considering broader opportunities for their own lives. As I gathered their insights - knowledge that might otherwise be overlooked or ignoredphotography and video as research and presentation tools became the means of stimulating memory as well as decentering power relations between myself as researcher and the women who shared. As these women re-tell their stories in the process of living out their lives, image and text move beyond the decisive moment in photographic time and space to invite engagement.

\section{An enormous shift occurred, as if before Christ and after Christ: before the Literacy Campaign and after the Literacy Campaign. The thinking of the people: of parents, of children, of aunts and uncles. Everyone changed.}




\section{Everyone left their houses ... everyone became literacy teachers. It was like an explosion: a desire to know, and to help those who did not know. - Carmen, Santiago de Cuba}

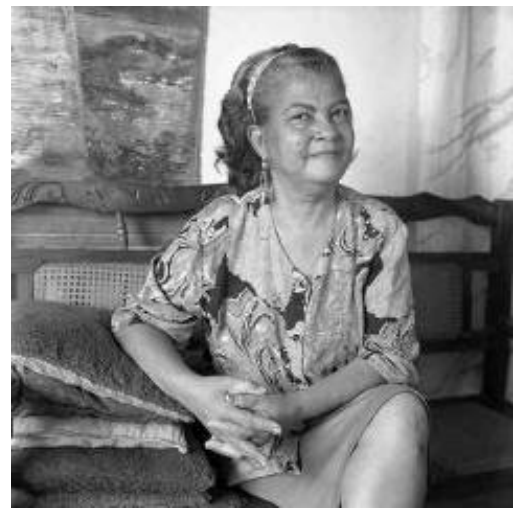

Figure 1: Eneida, Santiago de Cuba

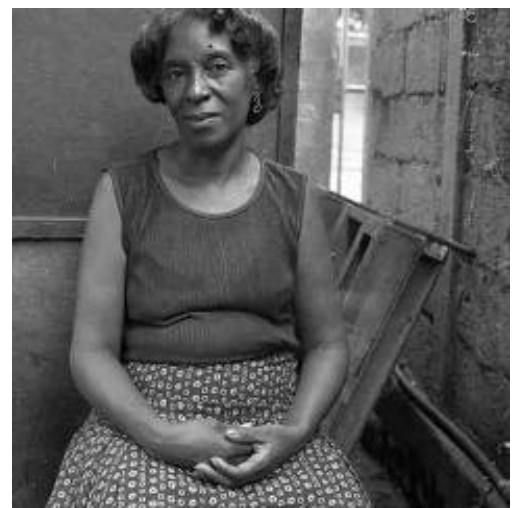

Figure 2: Elsa, Ciego de Avila

It is often assumed that the recording of history is evidence of something that has already happened - events that do not belong in present times - when choices we make in our daily lives are rooted in that which has already been. For those aspiring for social change, "things are not over"-there can be no end-"the story isn't finished, [and it] can never be finished," inviting new ways of contemplating the past can enable us to consider the possibility for change (Steedman, 1999, p. 48). The Cuban Revolution need not be perceived nor limited as a single event that occurred in 1959. Cubans themselves refer to the Revolution as an ongoing process, as social consciousness that continuously reinvents itself. Cuban scholar Rafael Hernández describes the paradoxes of Cubanology in broader, more fluid terms rather than as a fixed or defined area of study - as "visions of Cuba"-in connecting past events with present conditions to rethink possibility for the future (Hernández \& McClennen, 1997, p. 156).

With human experience dynamic and memory shifting over time, the photographic image - static or moving - can function as means to recall, reflect and reevaluate the significance of times past beyond the limitations of history in linear terms and the decisive act of clicking the shutter. With history abstract and accepted at face value - words on a page, fixed as a record, as part of the past that can be no more - the stories of a nation remain in the past, even if these stories are relevant to current times in the process of living out our lives. As Thelen (1995) purports, when history is kept open, dynamic and permeable, looking back to reflect upon accounts from the past can help explain present conditions and instill hope for the future. If history is kept in the past as something finished, that can be no more, how can we move ahead as a people? 


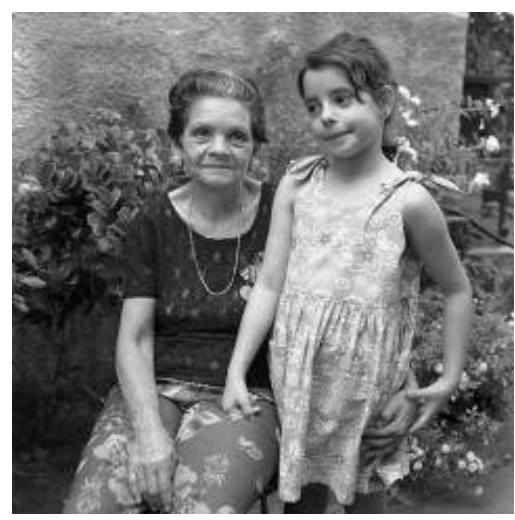

Figure 3: Lucy, Viñales

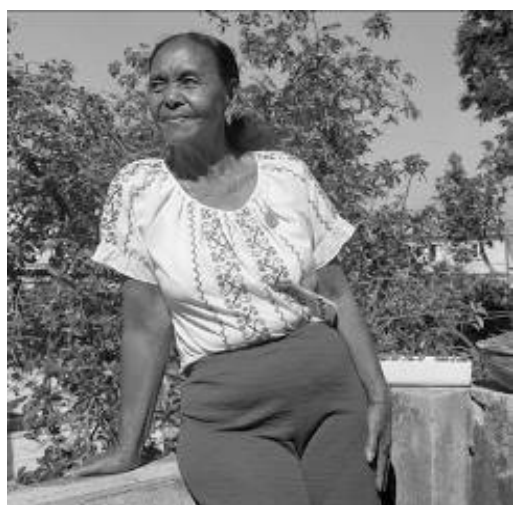

Figure 4: Isabel, Havana

This Literacy Campaign was the first major task of the Revolution, one that invited the people to become involved, en masse, to resolve whatever challenges faced by the country.

\section{And for this reason, this Campaign held great value: social value, economic value, political value ... it was the formation of our consciousness. \\ - Romalinda, Havana}

With educational reform a high priority in the early years of the Cuban Revolution, in 1961 more than 271,000 Cubans joined massive literacy brigades as part of a movement to eradicate illiteracy in the country within the year. To facilitate a mobilization of this size and grandeur, the Ministry of Education closed city schools for eight months so that young people of a minimum age and grade could be part of literacy brigades as an exercise of citizenship building. Known as brigadistas, they lived with peasant campesino families throughout Cuba for months at a time to share in the manual labor by day and to teach basic reading and writing skills at night. Their "students," about a million Cubans, had not had access to schooling due to race, gender and geographic isolation.

\section{Many campesinos had not yet received the bread of knowledge.}

The young people thus journeyed into remote areas of the country taking on the pleasure of teaching all how to read and write.

Their workbooks, their pencils, and their manuals: these were the arms they had, without a fear of anything. - Luris, Baracoa

As an artful researcher, I emphasize the extent to which visual media, and by extension the photograph, has long-since functioned as a kind of language that over time has enabled me to engage with my surroundings in the stirring of memory. As a wide-eyed teenager studying and traveling in Europe in the 1970s, I was riveted by otherwise everyday events that for me held broader social significance, challenging what I once thought of as "normal" in the North/Western standards of my upbringing. Faced with the unravelling of my 
own history and by questions that this raised in what I had otherwise considered and accepted as "truth," I came to realize the utmost importance of acknowledging stories that would be undervalued in the grand schema of knowledge production.

As if I had awoken with a new lens to view that before me, the photograph was symbolic of a new consciousness and an essential means for me to communicate this knowing.

To take on the challenge of raising the cultural awareness of the people, this Literacy Campaign was a necessity.

Libraries were then built...classrooms, in remote, mountainous regions.

Museums were opened, as venues to invite culture.

\author{
And with an illiterate people, \\ it's not possible to realize this type of social transformation. \\ It was, indeed, a necessity. \\ - Involvis, Baracoa
}

Then, as a student of photography I challenged traditional boundaries of photographic practice wanting to document the lives of others in a more poetic manner: a fleeting impression of who they might be, rather than one fixed in time. What I found unsettling was how the click of the shutter decisively framed one moment that became the monumental Truth, a hegemonic instrument shifting the subject-as-object into 'the' story, the accepted view. Visual stories locked human experience into the bowels of history, immortalized as "truth," a mechanical eye "showing you a world the likes of which only I can see" (Vertov, 1929; as cited in Robins 1998, p. 86). Years later, as a photographic witness to the sociocultural disruption that occurred in Central Europe post-1989, "I" could no longer accept how the camera, a primary tool of modernity, held the power of shaping history, an ideological lens to exclude stories that did not fit; or how the photograph was synonymous with "truth," "stenciled off the real," holding the capacity to privilege one group over another (Sontag 1979, p. 29).

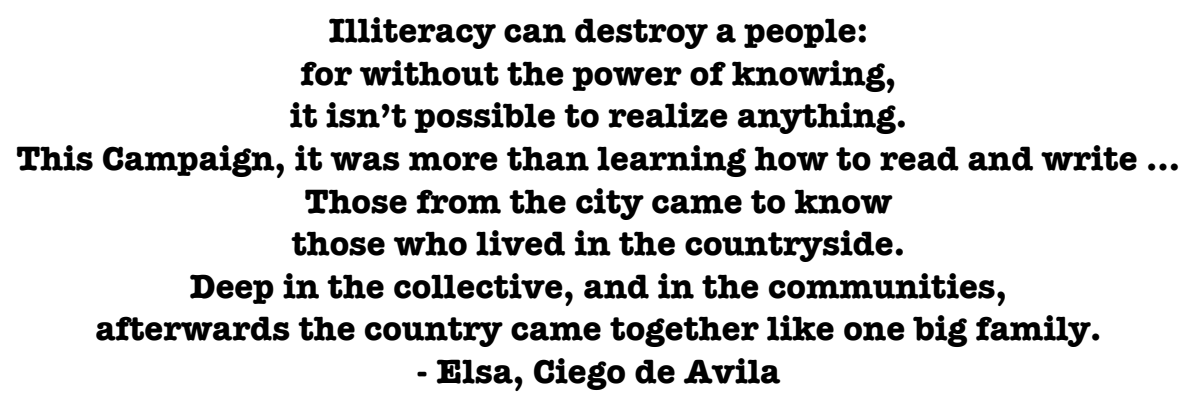

As the meaning and "value" of the photograph has relied upon the engagement of the onlooker looking inside the framed event, Cuba has similarly become a "marketplace" for outsiders who have tended to focus more on its presence as an ideological discourse than as a true society of lives lived (Hernández \& McClennen, 1997, pp. 143-4). Over time, broader constructs of 
power have limited the very essence of the photograph within a particular scope of understanding; similar to how the Cuban Revolution, an object of scrutiny and suspicion, has been shaped into a particular frame of reference. Yet, stories within the framework of the photograph and the Revolution, if left open and fluid as poetic renderings, could invite meaningful dialogue and exchange as well as contribute to social change.

This Revolutionary event, the Literacy Campaign, sparked the consciousness in the people to help others.

Those who became literate went on to become teachers themselves, to become doctors, qualified technicians, skilled workers.

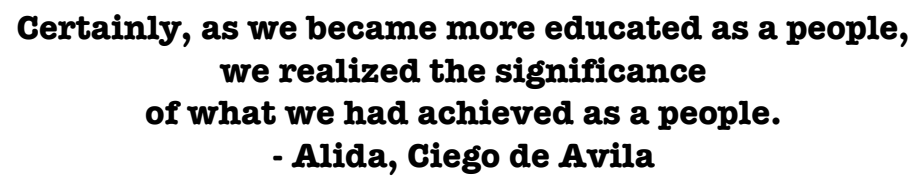

During the Literacy Campaign, of those who volunteered, more than 100,000 participants were middle-class urban youth between the ages of 10 and 19 who traveled to remote areas of Cuba to face challenges that were not "easy, safe or immediately rewarding" (Kozol, 1978, pp. 348-9). Integrated into the lives of campesino families, they came to know how the disenfranchised had lived "they will be teaching you what they have learned from the hard life... They will teach you the 'why' of the Revolution better than any speech, better than any book" (Castro, 1961; as cited in Keeble, 2001, p. 15).

In their growing awareness of social inequities and the promise of a better life for all, solidarity amongst Cubans evolved as young and old from different social and racial backgrounds exchanged knowledges and experiences, a revolutionary determinism that reinforced "feelings of common purpose, mutual support, and nationalism” (Bunck, 1994, p. 26). This Revolutionary movement has been a significant contribution to Cuba having achieved and then maintained the highest literacy rate in Latin America since its implementation; in the 1953 census, illiteracy was determined as $24.6 \%$ of the population, with rates in the countryside double than in urban centers (Jefferies, 1967).

The physical part of the writing process was so difficult for the older 'students'.

For many, the first time they had held a pencil.

To form the letters ... then, little by little, to form words.

One of my students cried tears of joy

the first time she was able to read a few words in a magazine.

What a revolutionary process:

to break from the chains of ignorance that once held them!

Once they understood what it meant to hold the light of knowledge women could then extend this knowing to their children.

- Betty, Ciego de Avila 
As an artful researcher, what I found to be significant was that more than half of those who volunteered as brigadistas were young women. The traditions and culture of pre-revolutionary Cuba had otherwise provided women with little opportunity beyond the expected familial role of wife/mother. In traditional terms, girls did not leave the house unescorted and parents made decisions on behalf of unmarried daughters to ensure their futures as "good" wives. Away from the family home for the first time, how she would envision possibility for her own life would no longer be the same.

\section{This was the first Revolutionary event for those of my age. IMyself, I was only 13 years old. \\ To participate in such a massive undertaking, well, it was a point of departure for me, in respect to my personal independence and identity, and the responsibilities that I took on as a young woman...}

\section{Living and working with the peasants, and then teaching them! \\ Everything about life in the countryside was so hard! \\ Carrying water up from the rivers, cooking over open fires, we learned so much from these women. \\ - Rosa, Havana}

My research has thus explored the participation of teenaged girls in the Literacy Campaign in 1961, one of many reforms happening in Cuba at that time; how this act of civil engagement would have acknowledged and reinforced the value of women within the Revolutionary framework in a very real and public sense. Listening to these stories years later, what is particularly striking was how the self-worth that ensued out of being part of a noble cause at a crucial moment in their country's history spurred these women to contemplate new and broader ways of viewing their own lives within the context of these changes: the revolution within the Revolution.

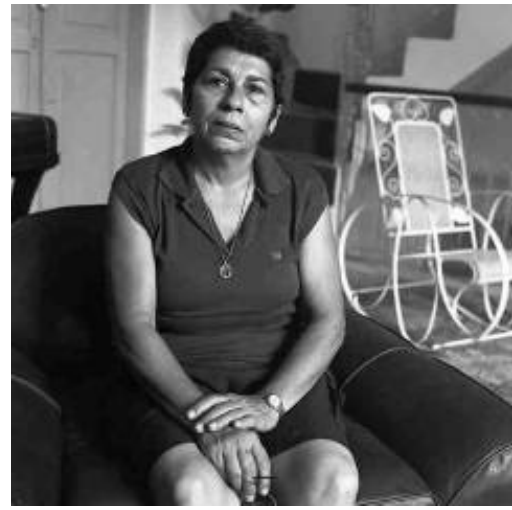

Figure 5: Moraina, Ciego de Avila

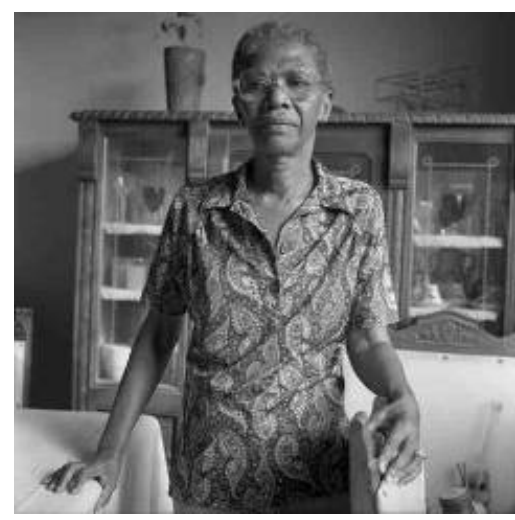

Figure 6: Melva, Camagüey 
My previous academic work had unfolded as a critical analysis of how institution as form imposes itself on the body, regulating how knowledge, subjectivity and vision have been historically framed and contained. I explored how the regulatory practice of thesis writing is contradictory to the spirit of academic pursuit, defining - and hence limiting - what type of knowledge was acceptable and held value in the academy. It was a constant struggle to contain myself within conventional forms of representation: "I would have liked to hear a sentence with room for me in it" (Cixous, 1985, p. 200).

Caught between world views and bound by descriptives, how could I ever articulate my "findings" within the "official" language of the academy and its "rationality of progress" (Sullivan, 1988, p. 33)? Even as I returned to the familiar, my photographic expression, I came to see how the tradition of photographing also remained suspect: "hunting" the subject, "framing" the shot, "taking" the photograph, and "fixing" a cordial exchange into a "good" photograph, as prescribed by the canon.

\section{An illiterate woman is chained to her responsibilities in the household. \\ She takes care of her husband, she cooks, irons \& attends to the children.}

\section{But an illiterate woman can't participate in society as a person, as a human being. \\ It's clear to me, she can be taken advantage of, if she can't defend herself. \\ Someone who is illiterate just doesn't know. And THAT's exploitation. \\ - Sarahi, Pinar del Rio}

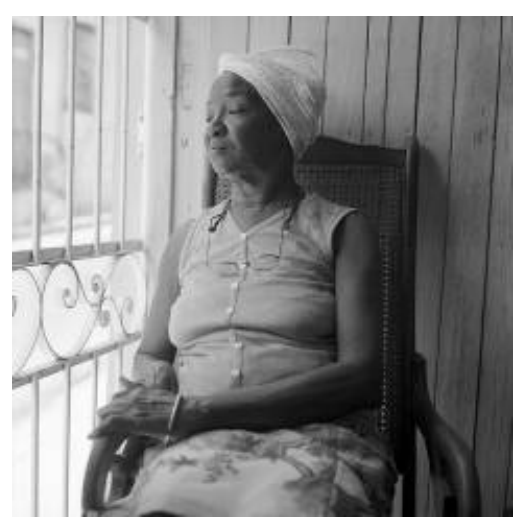

Figure 7: Oneida, Santiago de Cuba

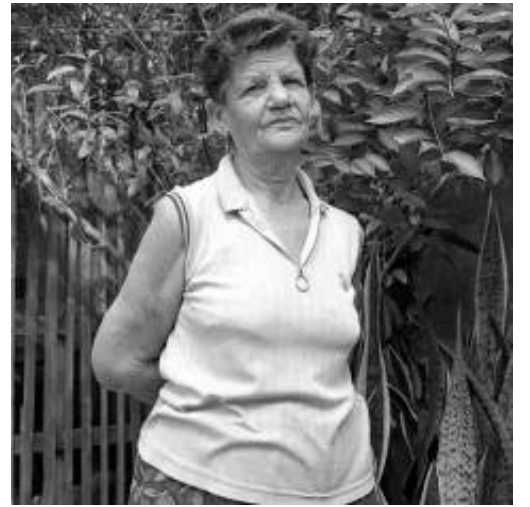

Figure 8: Humbelina, Pinar del Rio

Hélène Cixous' practice of l'écriture feminine-writing said to be feminine-speaks of how change from within is possible when taking age-old 
tools of oppression and transforming them into viable means of empowerment. I came to see how the standard approach to presenting research in itself was not the problem, only that "I" had accepted it in narrow terms, as limited. There was no need to step outside the methodological practice of words and images in an academic text; only the need to be more intuitively aware of the spatial elements within and beyond the margins on the page.

\section{For Cuban women, the Literacy Campaign was one grand life lesson. In the case of those who were the only girls in the family, some of their mothers also donned a uniform to join in the battle against illiteracy ...}

With the language of traditional photographic practice evoking an ideological lens that captures, frames, contains and regulates subjective experience in the mere click of the shutter, the blur of technical boundaries of digital media also calls for the photographer to take on moral and ethical responsibilities on image production and on no uncertain terms. My aim has been to redefine the patriarchal hold on photographic production and reimagining its potential as a poetic object. There is "more to the story" than what one sees in the photograph - the frame itself alludes to beyond-as the phenomena of the Revolution extends time and space from what it "should" be, to what it could be.

\section{For me, though, I became more independent as a young woman. In becoming a brigadista, this was the moment I took charge of my life. I became outgoing ... I became conscientious. I wasn't going to be tied down again! - Dora, Santiago de Cuba}

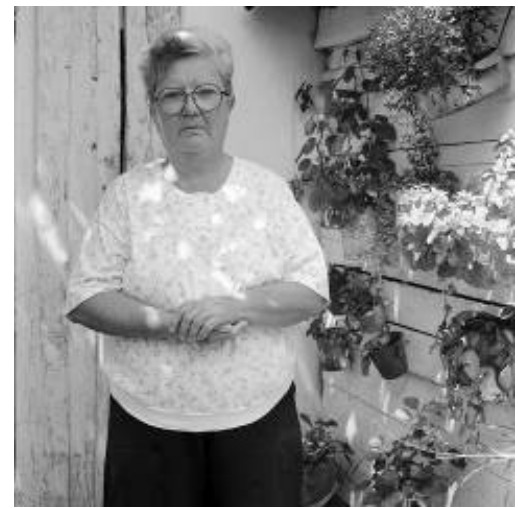

Figure 9: Magdalena, Viñales

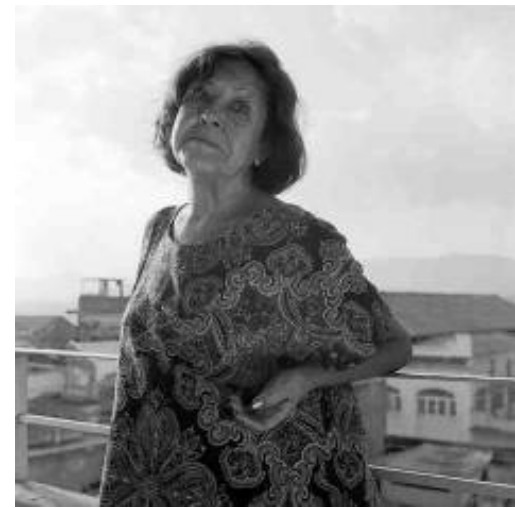

Figure 10: Carmen, Santiago de Cuba

As an artful researcher from outside the moment from times past, I am now invited into their homes and inside the poetic; back and forth in time, a non-linear experiencing of history. "Led beyond codes...no longer enclosed in the maps of social constructions," each woman recounts a memory unique to her "body" of 
text (Cixous 1991, p. 52). The photographs of these women together with video testimonials provide the visceral texture to the original event, the fabric of being human capable of transcending cultural barriers to touch us, as we are "moved by what we see in images" (Robins 1995, p. 39). Barthes describes this seeing, feeling and noticing as collective memory and mutual understanding, "a carnal medium, a skin I share with everyone" (1980, p. 42).

Beyond the mediations that hold the capacity to stir memory, as women we know how our stories--and those of our mothers, and those before-are not always considered as holding any value, and yet remain "written on the body...the accumulations of a lifetime" (Winterson, 1995, p. 89). As I engage with these women, I draw from my own experiences as an integral part of the research process, my "intentions, perceptions and actions" with memory extending and interpreting that which these women choose to share with me (Jongeward, 1997, p. 3). As they take steps not to forget, their stories claim space. The broader success of the Literacy Campaign cannot be merely fixed as data in how it reverberates in their lived presence, as the fundamental values, ideals and principles carry on from the past into present times. Stories, as they are remembered, build upon the history of a people.

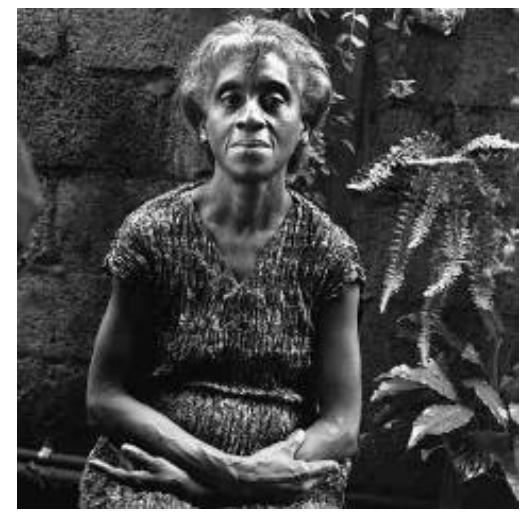

Figure 11: Bienvenida, Ciego de Avila

This Campaign left a definite mark on my life, In fact it changed everything for me.

I had thought of studying medicine,

but when I first went into the countryside and saw the need for teachers,

I changed my professional direction at once to dedicate myself to teaching.

All of this was confirmed in my personhood

after the murder of the young brigadista, Manuel Ascunce Domenech.

This was a terrible moment for the other literacy brigadistas

the majority in my group being young women.

We met together to watch the funeral on television, and to listen to the words of the President. Then, at the end of the funeral procession 


\section{we made a pact amongst ourselves: \\ To dedicate our lives to the educating of our people. - Nuria, Santiago de Cuba}

In a more urgent manner, I am certain that the inherent value of these stories was more implicit than the words themselves. What these women had learned was how they could contribute to the building of their country in a very real and public sense, by stepping outside of their familiar experience in one world to engage in another, as an integral part of their cubanidad; their historical memory of what it means to be Cuban beyond the Revolutionary process, for all times. As the Cuban Revolution continues to reinvent itself relative to exterior forces, what outsiders read as problematic in Cuba may well be assumptions they have "learned" through a particular ideological lens.

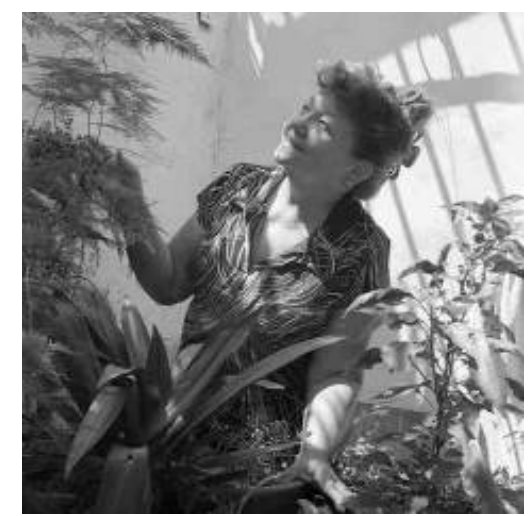

Figure 12: Nuria, Santiago de Cuba

This Campaign was such a gesture of humanity.

I believe it couldn't have happened without the participation of women.

Those of us who were part of it, we proved that together we could overcome obstacles, despite all the challenges we would undoubtedly face, socially or economically.

Yes, women ARF capable of taking on such tasks. - Zeida, Pinar del Rio

The stories of these women are not finished, and cannot be finished. Vignettes of experience as poetic interludes invite and engage the onlooker in the disruption and decentering of time and space to reach diverse audiences in - and outside the academy, when words alone fall short.

Yet, as an outsider invited inside the lives of a people, I proceed with caution through uneven spaces, with each "research" engagement as unique unto itself. With the photograph a token of memory, but as well a reminder of loss and of private anguish, what role do I play as researcher as Cuban women realize the broader implications of an historical event years later? How can this methodological approach facilitate interaction in another context and how might 
these meanings shift over time? Am I able to re/present these stories, to acknowledge the private space of women as well as respect the broader Revolution as dual realities, the "art of being in between" (de Certeau, 1984; as cited in Lather, 2007, p. 9)? Such stories, visual and otherwise, give light to Cuban women as they who already have it, points out Lizette Vila, noted Cuban television producer and filmmaker, "the illuminator of her surroundings" (Morris 2001).

Remembrance from times past, viewed as fluid, in a state of flux, is the story unfinished yet one borne of hope. And together our voices claim space, as together we take steps not to forget.

\section{References}

Barthes, R. (1981). Camera Lucia: Reflections on photography. Toronto: McGraw-Hill Ryerson Ltd.

Bunck, J. (1994). Fidel Castro, and the quest for a revolutionary culture in Cuba. University Park: The Pennsylvania State University Press.

Cixous, H. (1985). Angst (J. Levy, Trans.). London: John Calder.

Cixous, H. (1991). Coming to writing and other essays. New York: Routledge.

Hernández, R., and McClennen, S. (1997). The Paradoxes of Cubanology. In A. Fornet (Ed.), Bridging enigma: Cubans on Cuba [Special issue of South Atlantic Quarterly, 96(1), pp. 143157]. Durham: Duke University Press.

Jefferies, C. (1967). Illiteracy: A world problem. London: Pall Mall Press.

Jongeward, C. (1997). Visual Portraits: Integrating Artistic Process into Qualitative Research. Canadian Review of Art Education. 24(2), 1 - 19.

Keeble, A. (2001). In the spirit of wandering teachers. Melborne: Ocean Press.

Kozol, J. (1978). A new look at the literacy campaign in Cuba. Harvard Educational Review, 48, 341-377.

Lather, P. (2007). Getting lost: Feminist efforts toward a double(d) science. Albany, NY: State University of New York Press.

Morris, H. (2001). Adventure divas: Lizette Vila, host. Retrieved March 15, 2004, from http://www.pbs.org/adventuredivas/cuba/divas/vila.html

Richardson, L. (2002). Poetic representation of interviews. In J. Gubruim \& J. Holstein (Eds.), Handbook of interview research, context \& method (pp. 877-891). Thousand Oaks, CA: Sage Publications.

Robins, K. (1995). Will images move us still? In Martin Lister (Ed.). The photographic image in digital culture (pp. 29-50). New York: Routledge.

Sontag, S. (1978). On photography. New York: Prentice-Hall.

Steedman, C. (1999). Culture, cultural studies and the historians. In Simon During (Ed.), The cultural studies reader (pp. 47-56). New York: Routledge.

Sullivan, G. (1988). Arts practice as research: Inquiry in the visual arts. London: Sage Publications.

Thelen, D. (1995). History After the Enola Gay Controversy: An Introduction. Journal of American History, 82, Dec. 1995, 1029-1035.

Winterson, J. (1995). Art objects: Essays on ecstasy and effrontery. Toronto: Alfred A. Knopf.

Joanne C. Elvy has been a practicing photographer for over thirty years and is currently an "arts informed" Ph.D. student in the Adult Education Department in the Faculty of Education at the University of Toronto. She teaches sessionally in the History and Fine Arts departments at Algoma University in Sault Ste. Marie. Her scholarly work includes the interaction of culture and media in Cuban studies and international relations. 